\title{
Systematic review with network meta-analysis: indirect comparison of the efficacy of vonoprazan and proton-pump inhibitors for maintenance treatment of gastroesophageal reflux disease
}

\author{
Hiroto Miwa ${ }^{1} \cdot$ Ataru Igarashi $^{2} \cdot$ Lida Teng $^{2} \cdot$ Akihito Uda $^{3} \cdot$ Hisato Deguchi ${ }^{4}$. \\ Toshiro Tango 5
}

Received: 22 November 2018/Accepted: 14 March 2019/Published online: 27 March 2019

(C) The Author(s) 2019

\begin{abstract}
Background Long-term maintenance treatment of gastroesophageal reflux disease (GERD) is important to prevent relapse. Proton-pump inhibitors (PPIs) are used for both treatment and maintenance therapy of GERD. Recently, a potassium-competitive acid blocker vonoprazan was launched in Japan. We evaluated the comparative efficacy of vonoprazan and other PPIs for GERD maintenance.

Methods A systematic literature search was performed using MEDLINE and Cochrane Central Register of Controlled Trials. Double-blind randomized controlled trials (RCTs) of PPIs, vonoprazan, and placebo for GERD
\end{abstract}

Hiroto Miwa and Ataru Igarashi have contributed equally to this work.

Electronic supplementary material The online version of this article (https://doi.org/10.1007/s00535-019-01572-y) contains supplementary material, which is available to authorized users.

Hiroto Miwa

miwahgi@hyo-med.ac.jp

1 Division of Gastroenterology, Department of Internal Medicine, Hyogo College of Medicine, 1-1 Mukogawa, Nishinomiya, Hyogo 663-8501, Japan

2 Department of Health Economics and Outcomes Research, Graduate School of Pharmaceutical Sciences, The University of Tokyo, Hongo 7-3-1, Bunkyo-ku, Tokyo 113-0033, Japan

3 Japan Medical Affairs, Takeda Pharmaceutical Company Ltd, 1-1, Nihonbashi-honcho 2-chome, Chuo-ku,

Tokyo 103-8668, Japan

4 Japan Medical Affairs, Takeda Pharmaceutical Company Ltd, 1-1, Doshomachi 4-chome, Chuo-ku, Osaka 541-0054, Japan

5 Center for Medical Statistics, 2-9-6 Higashi Shimbashi, Minato-ku, Tokyo 105-0021, Japan maintenance published in English or Japanese were selected. Among them, studies conducted at the recommended dose and for the recommended use, and containing information on maintenance rate based on endoscopic assessment, were included. The comparative efficacies of treatments were estimated by performing a Bayesian network meta-analysis, which assessed the consistency assumption. Outcomes were number or rate of patients who maintained remission.

Results Of 4001 articles identified, 22 RCTs were eligible for analysis. One study published as an abstract was handsearched and added. The consistency hypothesis was not rejected for the analysis. The odds ratio of vonoprazan $10 \mathrm{mg}$ to each PPI was 13.92 (95\% credible interval [CI] $1.70-114.21)$ to esomeprazole $10 \mathrm{mg} ; 5.75(95 \% \mathrm{CI}$ $0.59-51.57)$ to rabeprazole $10 \mathrm{mg} ; 3.74 \quad(95 \% \quad \mathrm{CI}$ $0.70-19.99$ ) to lansoprazole $15 \mathrm{mg}$; and 9.23 (95\% CI $1.17-68.72$ ) to omeprazole $10 \mathrm{mg}$.

Conclusions The efficacy of vonoprazan in GERD maintenance treatment may be higher than that of some PPIs. However, a direct comparison of vonoprazan and PPIs is required to confirm these effects.

Keywords Gastroesophageal reflux disease - Network meta-analysis · Potassium-competitive acid blocker . Proton-pump inhibitor · Vonoprazan

\section{Introduction}

Gastroesophageal reflux disease (GERD) is a chronic digestive disorder resulting from the reflux of gastric contents into the esophagus and is often accompanied by symptoms of heartburn, regurgitation, and dysphagia [1]. Currently, acid suppressive therapy using proton-pump 
inhibitors (PPIs) is recommended as a first-line treatment for GERD [2]. Although symptomatic relief and acute healing of esophageal lesions can be achieved by shortterm treatment with PPIs, $50-80 \%$ of patients experience relapse within 6 months to 1 year after termination of effective therapy [3]. Repeated relapses not only lead to poorer health-related quality of life, but also increase the risk of developing major complications, such as esophageal stricture, ulceration, or Barrett's esophagus [4, 5]. Therefore, long-term continuous maintenance treatment with drugs that are safe and tolerable is required for some patients with GERD [6].

PPIs are currently used for the long-term treatment of patients with recurrent GERD. Although PPIs achieve better acid suppression and show higher tolerability than conventionally used histamine $\mathrm{H}_{2}$-receptor antagonists $\left(\mathrm{H}_{2} \mathrm{RAs}\right)$, approximately half of the patients treated with PPIs experience incomplete gastric acid control during the nighttime, a phenomenon called nocturnal gastric acid breakthrough, which makes the disease intractable [7]. Shorter half-life and requirement of acid activation impair the efficacy of PPIs, particularly during the nighttime, leading to nocturnal gastric acid breakthrough.

Vonoprazan is a novel, potassium-competitive acid blocker (P-CAB) launched in 2015. P-CABs are stable in acidic environments and exert more potent and prolonged acid-inhibitory effects than PPIs [8]. However, early P-CABs, which have an imidazopyridine ring structure, were reported to cause hepatic toxicity when administered repeatedly [9]. Vonoprazan offers a favorable safety profile for long-term maintenance treatment owing to the absence of an imidazopyridine ring, which is associated with increased transmission to the liver $[8,10]$. A randomized controlled trial (RCT) verified both non-inferiority and superiority of vonoprazan to lansoprazole, one of the most commonly used PPIs, for 24-week maintenance treatment of GERD [10]. However, no information is available on the comparative efficacy of vonoprazan and PPIs other than lansoprazole for the maintenance treatment of GERD. Therefore, we conducted a Bayesian network meta-analysis, which combines both direct and indirect evidence of multiple RCTs, to compare the maintenance efficacy of vonoprazan versus PPIs. The results of our study aim to provide clinicians with useful information to offer better maintenance treatment for patients with GERD who have repeated relapse.

\section{Methods}

The protocol of this study was prospectively registered at PROSPERO (registration number CRD42015024880). This study was conducted using the recommended approaches of the Cochrane Handbook for Systematic Reviews of Interventions [11] and reported according to the PRISMA statement [12] and the PRISMA extension for network meta-analysis [13].

\section{Data sources and searches}

Two databases, MEDLINE (all years up to January 6, 2016) and Cochrane Central Register of Controlled Trials (CENTRAL, all years up to November 2015), were used for the literature search. One abstract for a known study that was not yet published as a manuscript on MEDLINE or CENTRAL was hand-searched.

\section{Study selection}

The studies included in this systematic literature search were double-blind RCTs published in English or Japanese that met the following criteria: (a) adult GERD patients; and (b) treatment with a PPI, vonoprazan, or placebo. Abstracts were hand-searched. The following studies were excluded: (a) were not conducted at the usual dosage (e.g., recommended dosage and administration in Japan); (b) did not have patient number; (c) did not have information on maintenance effect based on an endoscopic assessment; and (d) contained only relapse rate and did not contain information on the number of patients in whom GERD was maintained effectively based on either the observed number or life table estimate. Supplementary Table S1 and Fig. 1 show the strategy and algorithm for study selection. The outcomes were either number or rate of patients who maintained remission.

\section{Data extraction}

From the selected articles, either the number of patients who maintained remission during the study period, as confirmed by endoscopy, or the remission rate based on endoscopic evaluation was extracted from each treatment group. If there were several end points in one RCT, data from the latest time point were extracted. The data were analyzed by the intention-to-treat (ITT) approach. If ITT data were not available, completer-only data were used during the analysis. If both the observed remission rate and life table using Kaplan-Meier estimates were available, then the observed remission rate was preferentially used. When only a lifetime estimate was available, the number of patients who remained healed was calculated by multiplying the estimated remission rate at the latest end point and ITT population. 
Fig. 1 Flowchart summarizing the exclusion criteria of the articles

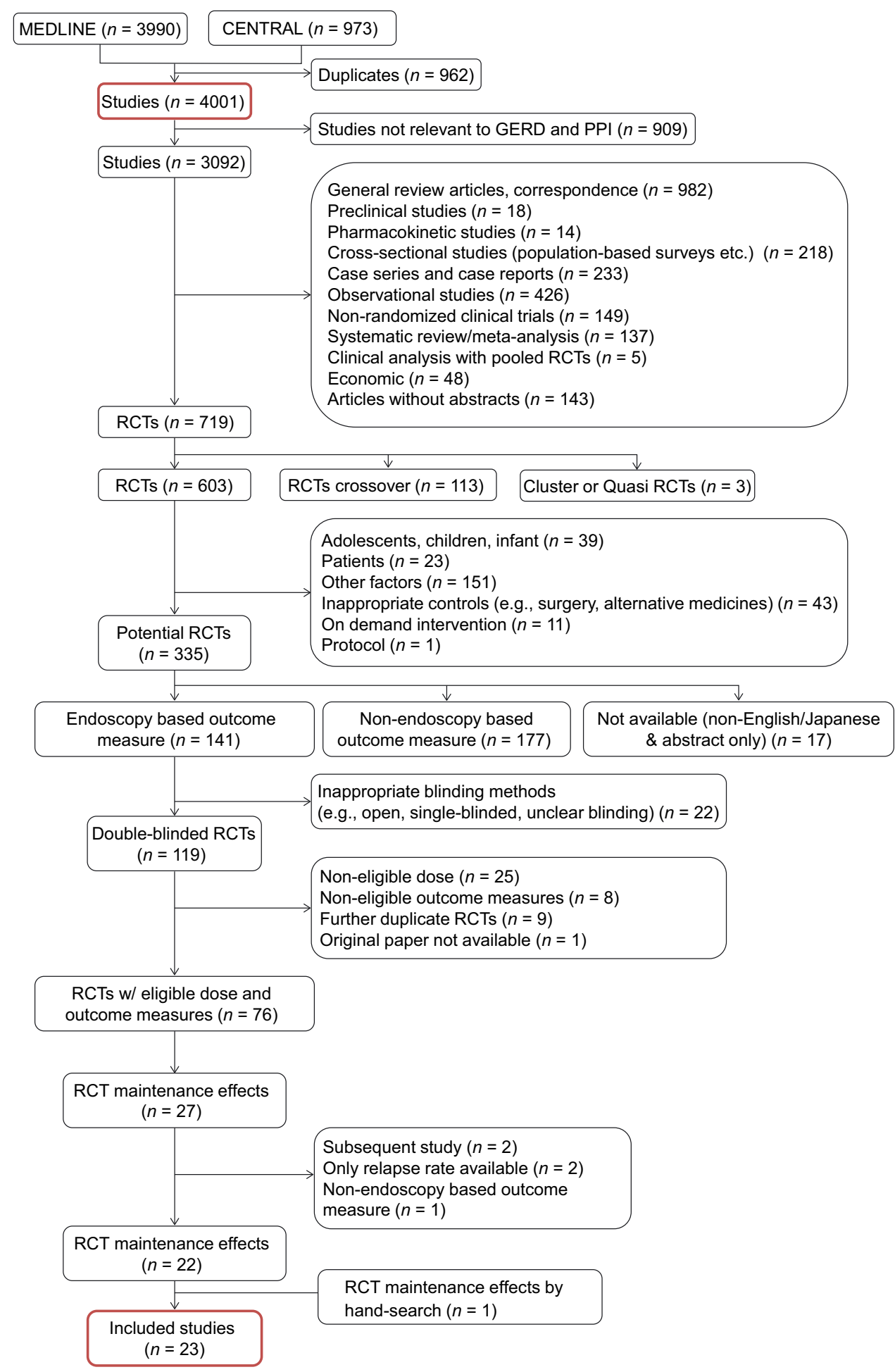

For the main analysis, the maintenance rate at the latest observation point (24-260 weeks) was extracted. For subgroup analysis, the remission rate or number of patients who remained healed at 6 months (or 24 weeks) was extracted if available.

\section{Quality assessment}

The risk of bias was assessed using the Cochrane Risk of Bias Tool for RCTs, and sensitivity analysis was conducted by excluding studies with a high risk of bias. 


\section{Data synthesis and analysis}

Network meta-analyses based on the hierarchical Bayesian logistic models [14, 15] and using the Markov Chain Monte Carlo (MCMC) methods were conducted using the WinBUGS software (MRC Biostatistics Unit, Cambridge, UK). For comparing the efficacy of treatments, we calculated the odds ratios (OR) with $95 \%$ credible interval (CI). A key assumption when conducting network meta-analyses is that the analyzed network is consistent, with no conflicts between direct and indirect evidence [16]. To assess inconsistency, we fitted an inconsistency model and calculated the global Wald test statistic (Bayesian version of Wald test statistic) for all inconsistency parameters [14]. A $p$ value $>0.05$ indicated inconsistency. The network metaanalysis was conducted by applying the consistency model described by White et al. [14]. Since the model was based on a same between-studies variance model, another analysis was also conducted with a same between-studies variance model and an unstructured variance model, both described by $\mathrm{Lu} \mathrm{G}$ et al. [15]. When performing the MCMC analysis, two chains were used in parallel with a burn-in of 100,000 updates in each chain, and the next 100,000 updates were used for analysis. The updating frequency of chain per one update was set as 10 , while that of the unstructured variance model by Lu et al., in which autocorrelation appeared strongly, was set as 20. Diagnostic tools such as trace plots and Brooks-Gelman-Rubin statistics were assessed to confirm the convergence of the Markov chain. The model fit of each analysis was assessed by deviance information criterion (DIC) [17].

Sensitivity analyses were conducted to examine the validity and robustness of the main analysis by the following methods: (a) excluding studies having high risk of bias; (b) excluding studies in which the remission rate was calculated based on per-protocol set (PPS) population, or those in which only life table (or Kaplan-Meier) estimated the remission rates; (c) only using studies assessing grades of erosive esophagitis by the Los Angeles grading method [18]; or (d) only using studies that applied a high standard for maintenance (remission was defined as grade A by the Los Angeles scale or grade 1 by Hentzel-Dent [19] or Savary-Miller scale [20], or 0/normal mucosa).

\section{Results}

The systematic literature search identified 4001 studies from the databases. The search criteria and the number of articles selected per each criterion are shown in Supplementary Table S1. Among them, 23 RCTs were eligible for analysis, which included one abstract [10] selected by hand-searching (Table 1). Figure 1 shows the process of searching as well as the number of included and excluded studies. The data of two other studies [21,22] were adopted for subgroup analysis instead of one study (Study ID 719 included in the main analysis) [23], because they reported the results of the same RCT at different time points (Table 1). Nine drugs including vonoprazan, six PPIs (dexlansoprazole, esomeprazole, rabeprazole, pantoprazole, lansoprazole, and omeprazole), one $\mathrm{H}_{2} \mathrm{RA}$ (ranitidine), and placebo were extracted for the main analysis; and eight drugs (excluding pantoprazole from the main analysis) were extracted for subgroup analysis (Fig. 2). All types of PPIs that have been sold in Japan for the treatment of GERD were included. The direct comparison of treatment for the main analysis is shown in Fig. 2a, and that for subgroup analysis is shown in Fig. 2b. Of the 23 studies, two studies were judged to have a high risk of bias (Fig. 3).

The global Wald test showed $p>0.05$ in both main analysis and subgroup analysis (Table 2). Consequently, the consistency hypothesis was not rejected for the analyses, and thus, the network meta-analysis was conducted. In the main analysis, placebo, two treatments with vonoprazan, ten treatments with PPIs, and two treatments with $\mathrm{H}_{2}$ RAs distinguished by general names and their dosages were included. The OR of each treatment to placebo from the consistency model by White et al. was calculated as shown in Table 3. In the present analysis, DIC with the model by White et al. was 111.78 , which was comparable to that with the same between-studies variance model (111.35) by Lu et al. (Table 3). In the unstructured variance model by Lu et al., the variance could not be assessed in some PPIs owing to an insufficient number of studies compared with the large number of variance parameters, and the DIC was higher than that of the same betweenstudies variance model. Consequently, the consistency model was suggested to fit well. The OR with its 95\% CI for each treatment to placebo in the main analysis is shown in Table 3. Treatment with vonoprazan and PPIs, regardless of dose, showed significantly higher maintenance effect than placebo. Although ranitidine showed a tendency toward high maintenance effect, it was not significant (Table 3). The OR of vonoprazan $10 \mathrm{mg}$ to other PPIs prescribed in Japan was as follows: 13.92 (95\% CI $1.70-114.21)$ to esomeprazole $10 \mathrm{mg} ; 5.75(95 \% \mathrm{CI}$ $0.59-51.57)$ to rabeprazole $10 \mathrm{mg} ; 3.74 \quad(95 \%$ CI $0.70-19.99)$ to lansoprazole $15 \mathrm{mg}$; and 9.23 (95\% CI 1.17-68.72) to omeprazole $10 \mathrm{mg}$ (Fig. 4a). We also assessed the efficacy of vonoprazan $20 \mathrm{mg}$ to other PPIs, and the ORs were calculated as follows: 38.71 (95\% CI 4.65-333.62) to esomeprazole $10 \mathrm{mg} ; 16.93$ (95\% CI 2.07-140.61) to rabeprazole $10 \mathrm{mg} ; 10.55(95 \%$ CI 1.84-65.50) to lansoprazole $15 \mathrm{mg}$; and 27.11 (95\% CI 3.30-221.41) to omeprazole $10 \mathrm{mg}$ (Fig. 4b). The ORs of 
Table 1 List of included articles used in the main analysis and those used only in the subgroup analysis (instead of Study ID 710 in the main analysis)

\begin{tabular}{|c|c|c|c|c|}
\hline $\begin{array}{l}\text { Study } \\
\text { ID }\end{array}$ & Author(s) & $\begin{array}{l}\text { Publication } \\
\text { year }\end{array}$ & Treatment (sample size) & $\begin{array}{l}\text { End } \\
\text { point }\end{array}$ \\
\hline \multicolumn{5}{|c|}{ Main analysis } \\
\hline 111 & $\begin{array}{l}\text { Thjodleifsson et al. } \\
\text { [35] }\end{array}$ & 2000 & Rab $10 \mathrm{mg}(n=82)$ versus $\operatorname{Rab} 20 \mathrm{mg}(n=78)$ versus Ome $(n=83)$ & 1 year \\
\hline 439 & Laursen et al. [24] & 1995 & Ome $10 \mathrm{mg}(n=64)$ versus Ome $20 \mathrm{mg}(n=65)$ versus Pla $(n=29)$ & 6 months \\
\hline 710 & Caos et al. [23] & 2005 & Rab 20 mg $(n=163)$ versus Rab $10 \mathrm{mg}(n=165)$ versus Pla $(n=169)$ & 5 years \\
\hline 936 & Richter et al. [33] & 2004 & Pan 40 mg $(n=85)$ versus Rani 150 mg TD $(n=88)$ & 1 year \\
\hline 1234 & Lauritsen et al. [25] & 2003 & Eso $20 \mathrm{mg}(n=522)$ versus Lan $15 \mathrm{mg}(n=486)$ & 6 months \\
\hline 1469 & Vakil et al. [26] & 2001 & Eso $20 \mathrm{mg}(n=98)$ versus Eso $10 \mathrm{mg}(n=91)$ versus Pla $(n=94)$ & 6 months \\
\hline 1516 & Johnson et al. [27] & 2001 & Eso $20 \mathrm{mg}(n=82)$ versus Eso $10 \mathrm{mg}(n=77)$ versus Pla $(n=77)$ & 6 months \\
\hline 2040 & Devault et al. [28] & 2006 & Eso $20 \mathrm{mg}(n=512)$ versus Lan $15 \mathrm{mg}(n=514)$ & 6 months \\
\hline 3551 & Peura et al. [36] & 2009 & Lan $15 \mathrm{mg}(n=83)$ versus Rani $150 \mathrm{mg}$ TD $(n=81)$ & 1 year \\
\hline 3574 & Annibale et al. [29] & 1998 & Ome 20 mg $(n=102)$ versus Rani 150 mg TD $(n=103)$ & 6 months \\
\hline 3579 & Robinson et al. [37] & 1996 & Lan $30 \mathrm{mg}(n=56)$ versus Lan $15 \mathrm{mg}(n=59)$ versus Pla $(n=55)$ & 1 year \\
\hline 3619 & Metz et al. [30] & 2009 & Dexlan MR 30 mg $(n=140)$ versus Pla $(n=147)$ & 6 months \\
\hline 3627 & Metz et al. [34] & 2003 & Pan 40 mg $(n=94)$ versus Rani 150 mg TD $(n=95)$ & 1 year \\
\hline 3633 & Bardhan et al. [31] & 1998 & Ome $10 \mathrm{mg}(n=130)$ versus Pla $(n=133)$ & 6 months \\
\hline 3843 & Hatlebakk et al. [40] & 1997 & Lan $15 \mathrm{mg}(n=50)$ versus Lan $30 \mathrm{mg}(n=53)$ & 1 year \\
\hline 3850 & Gough et al. [32] & 1996 & $\begin{array}{l}\text { Lan } 15 \mathrm{mg}(n=86) \text { versus Lan } 30 \mathrm{mg}(n=75) \text { versus Rani } 300 \mathrm{mg} \text { TD } \\
\quad(n=74)\end{array}$ & 1 year \\
\hline 3851 & Sontag et al. [20] & 1996 & Lan $15 \mathrm{mg}(n=50)$ versus Lan $30 \mathrm{mg}(n=49)$ versus Pla $(n=47)$ & 1 year \\
\hline 3863 & Vigneri et al. [41] & 1995 & Rani $150 \mathrm{mg} 3 \mathrm{TD}(n=35)$ versus Ome $20 \mathrm{mg}(n=35)$ & 1 year \\
\hline 3869 & Bate et al. [38] & 1995 & Ome $10 \mathrm{mg}(n=60)$ versus Ome $20 \mathrm{mg}(n=68)$ versus Pla $(n=62)$ & 1 year \\
\hline 3878 & Hallerback et al. [39] & 1994 & $\begin{array}{l}\text { Ome } 20 \mathrm{mg}(n=131) \text { versus Ome } 10 \mathrm{mg}(n=82) \text { versus Rani } 150 \mathrm{mg} \text { TD } \\
(n=128)\end{array}$ & 1 year \\
\hline 3886 & Dent et al. [53] & 1994 & Ome $20 \mathrm{mg}(n=53)$ versus Rani $150 \mathrm{mg}$ TD $(n=51)$ & 1 year \\
\hline 3922 & Lundell et al. [54] & 1991 & Ome $20 \mathrm{mg}(n=46)$ versus Rani $150 \mathrm{mg}$ TD $(n=22)$ & 1 year \\
\hline Abst & Umegaki et al. [10] & 2014 & Von $10 \mathrm{mg}(n=197)$ versus Von $20 \mathrm{mg}(n=201)$ versus $\operatorname{Lan} 15 \mathrm{mg}(n=196)$ & 6 months \\
\hline \multicolumn{5}{|c|}{ Subanalysis only } \\
\hline 45 & Caos et al. [21] & 2000 & Rab $20 \mathrm{mg}(n=69)$ versus Rab $10 \mathrm{mg}(n=70)$ versus Pla $(n=70)$ & 1 year \\
\hline 79 & Birbara et al. [22] & 2000 & Rab $20 \mathrm{mg}(n=93)$ versus Rab $10 \mathrm{mg}(n=93)$ versus Pla $(n=99)$ & 1 year \\
\hline
\end{tabular}

Abst abstract, Dexlan dexlansoprazole, Eso esomeprazole, Lan lansoprazole, Ome omeprazole, Pan pantoprazole, Pla placebo, Rab rabeprazole, Rani ranitidine, $T D$ twice daily, Von vonoprazan

all combinations among the different treatments are shown in Supplementary Table S2.

As the latest end point of each study varied between 6 months and 5 years, a subgroup analysis was conducted using the data obtained at 6 months to confirm the robustness of the results. Twelve studies [10, 21, 22, 24-32] with a healing rate at 6 months based on endoscopic assessment were included. DIC in this analysis was 63.08, which was almost the same as that with the same between-studies variance model (62.50) by Lu et al. (Table 3). The efficacy of vonoprazan $10 \mathrm{mg}$ to PPIs based on the subgroup analysis was expressed as ORs as follows: 10.40 (95\% CI 1.54-67.02) to esomeprazole
$10 \mathrm{mg} ; 3.17$ (95\% CI $0.37-25.23$ ) to rabeprazole $10 \mathrm{mg}$; 3.81 (95\% CI 0.94-14.92) to lansoprazole $15 \mathrm{mg}$; and 3.70 (95\% CI 0.29-26.68) to omeprazole $10 \mathrm{mg}$ (Fig. 4c).

Sensitivity analyses were conducted by including/excluding the following studies: (a) excluding two studies [33, 34] with high risk of bias (Fig. 3); (b) excluding 15 studies, including one study [28] that calculated healing rate based on PPS, and 14 studies [23-27, 29, 31, 33-39] with Kaplan-Meier estimates; (c) including six studies [10, 25-28, 30] that used the Los Angeles scale for endoscopic assessment; and (d) including 10 studies [10, 24-28, 30, 32, 40, 41] that applied high standard of maintenance. Consistency hypothesis was not rejected for 

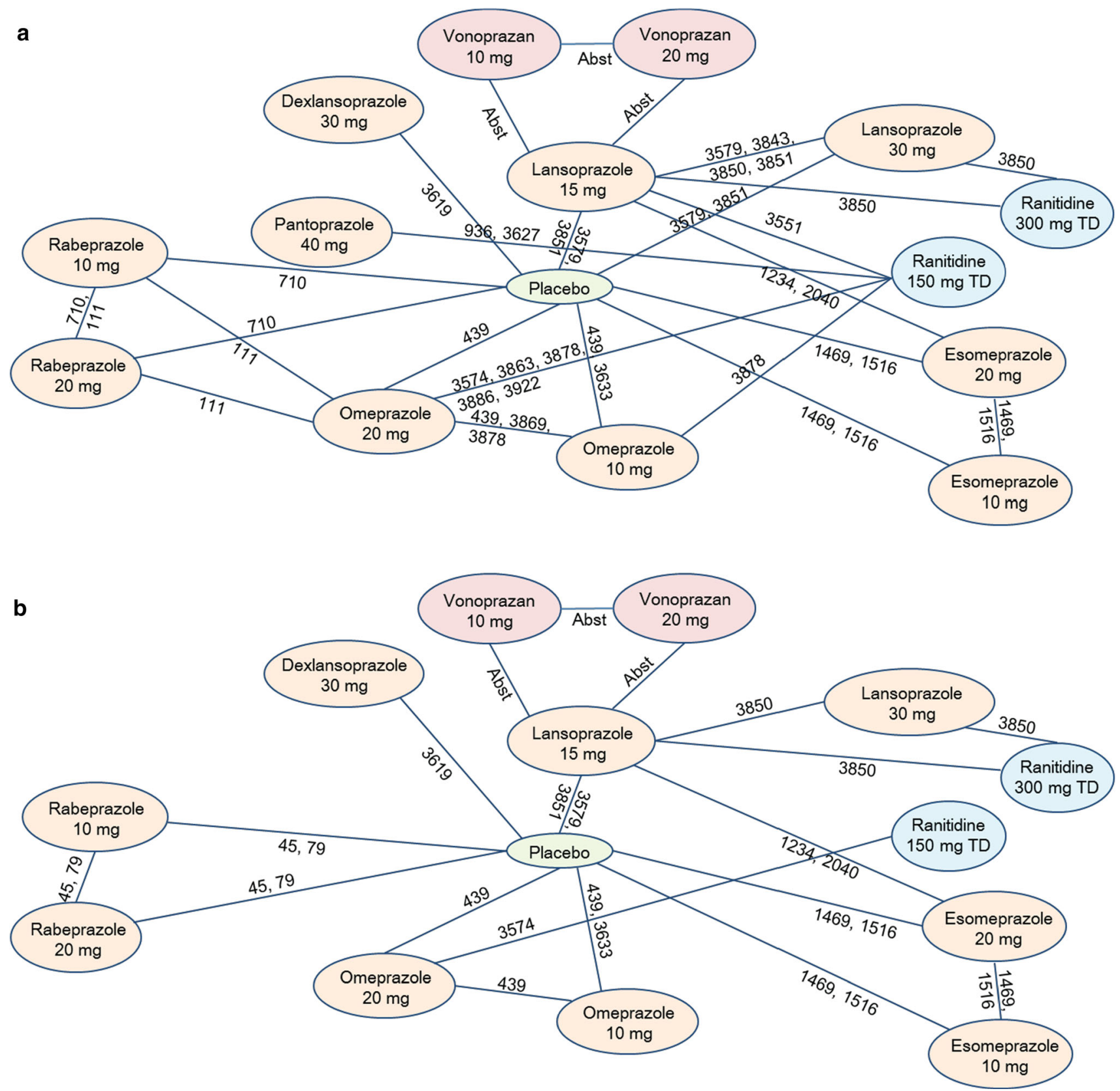

Fig. 2 Direct comparison networks for a main analysis (the latest end point was assessed) and b subgroup analysis (end point was assessed at 6 months). Red, vonoprazan; orange, proton-pump inhibitor; blue,

sensitivity analyses, except for analysis c, where the degree of freedom was 0 and, consequently, its consistency could not be assessed. The results (the estimates and orders) of analyses a-c were consistent with those of the main analysis. However, different results were obtained in analysis d; for vonoprazan $10 \mathrm{mg}$, a significantly higher effect to lansoprazole $15 \mathrm{mg}$ was observed, but not to omeprazole $10 \mathrm{mg}$ (Supplementary Table S3). histamine $\mathrm{H}_{2}$-receptor antagonist; green, placebo. The numerical values indicate Study IDs, which are consistent with those presented in Table 1. Abst abstract, $T D$ twice daily

\section{Discussion}

In this network meta-analysis, we aimed to evaluate the comparative efficacy of vonoprazan and other PPIs for the maintenance of GERD. The GERD maintenance effect with vonoprazan $10 \mathrm{mg}$ was significantly higher than that with esomeprazole $10 \mathrm{mg}$ and omeprazole $10 \mathrm{mg}$, but not higher than that with other PPIs prescribed in Japan. Vonoprazan $(20 \mathrm{mg}$ ) showed significantly higher efficacy than rabeprazole $10 \mathrm{mg}$ and lansoprazole $15 \mathrm{mg}$ besides 
Fig. 3 Risk of bias for included randomized controlled trials: a proportion of studies with each of the judgment, $\mathbf{b}$ all judgments in a cross-tabulation of study by entry. Green $(+)$, low risk of bias; yellow (?), unclear risk of bias; red (-), high risk of bias. The numerical values indicate Study IDs, which are consistent with those presented in Table 1

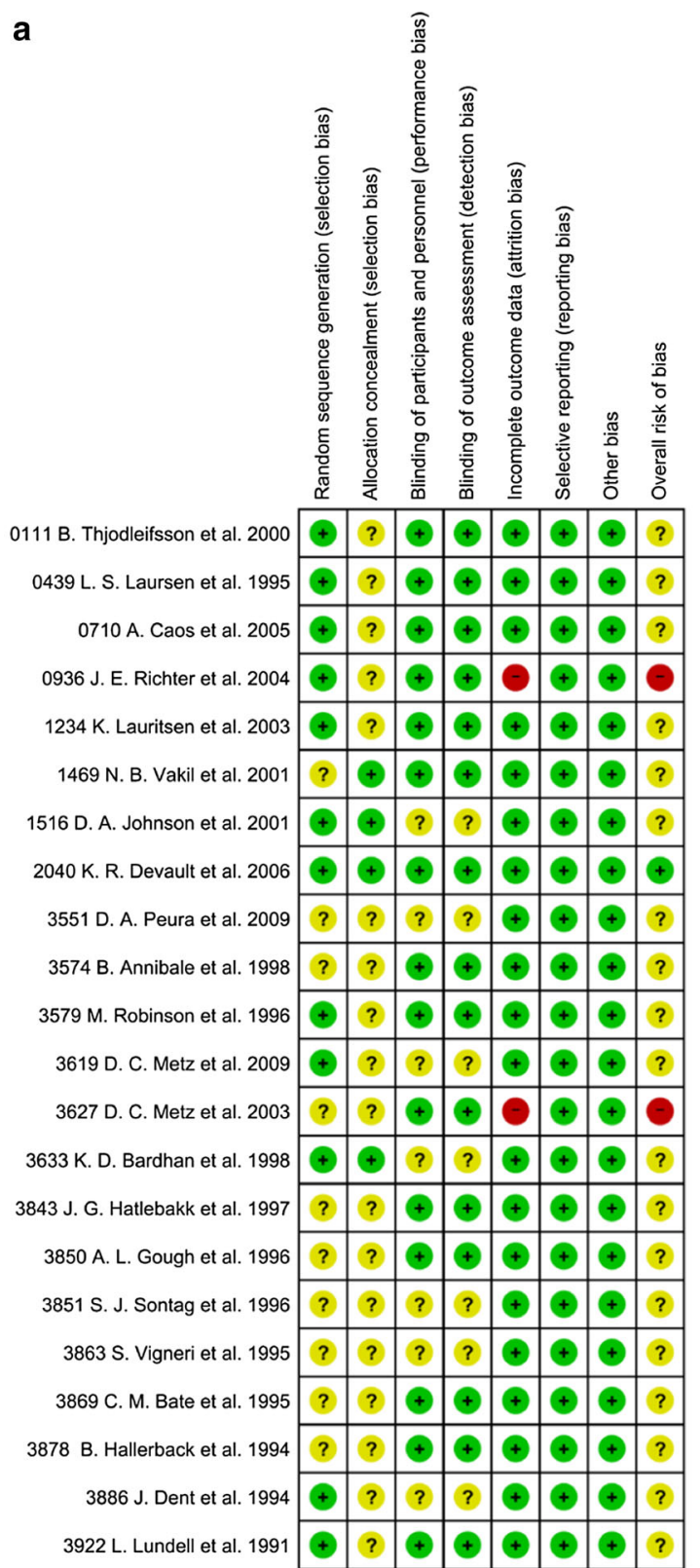

b

Random sequence generation (selection bias)

Allocation concealment (selection bias)

Blinding of participants and personnel (performance bias)

Blinding of outcome assessment (detection bias)

Incomplete outcome data (attrition bias)

Selective reporting (reporting bias)

Other bias

Overall risk of bias

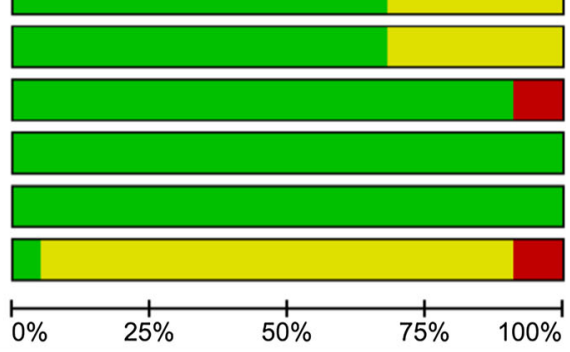

Low risk of bias

Unclear risk of bias

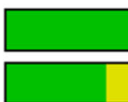

High risk of bias 
Table 2 Results of inconsistency test

\begin{tabular}{llll}
\hline & Degree of freedom & Wald-like statistics & $p$ value \\
\hline Main analysis & 9 & 13.8 & 0.131 \\
Subgroup analysis & 1 & 2.3 & 0.128 \\
Sensitivity analysis & & & 12.7 \\
$\quad$ (a) Excluding high ROB studies & 9 & 1.0 & 0.177 \\
(b) Excluding studies using PPS or KM & 2 & - & 0.596 \\
(c) Only studies using LA grading & 0 & 0.0 & - \\
(d) Only studies with high standard of maintenance & 1 & 0.882 \\
\hline
\end{tabular}

KM Kaplan-Meier, LA Los Angeles, PPS per-protocol set, ROB risk of bias

Table 3 Odds ratios of relative maintenance effects in each treatment to placebo in main analysis (the latest end point was assessed) and subgroup analysis (end point was assessed at 6 months)

\begin{tabular}{|c|c|c|c|c|}
\hline \multirow[t]{2}{*}{ Treatment (versus Placebo) } & \multicolumn{2}{|c|}{ White et al. [14] consistency model } & \multicolumn{2}{|c|}{ (Reference) Lu and Ades [15] same between-studies variance model } \\
\hline & Estimate & $(95 \% \mathrm{CI})$ & Estimate & $(95 \% \mathrm{CI})$ \\
\hline \multicolumn{5}{|c|}{ Main analysis (the latest end point was assessed) } \\
\hline Vonoprazan $10 \mathrm{mg}$ & 46.48 & $(7.11-305.21)$ & 48.57 & $(9.38-254.68)$ \\
\hline Vonoprazan $20 \mathrm{mg}$ & 131.37 & $(17.27-1053.63)$ & 138.52 & $(15.26-1344.80)$ \\
\hline Dexlansoprazole $30 \mathrm{mg}$ & 8.32 & $(1.67-41.26)$ & 8.36 & $(2.12-33.25)$ \\
\hline Esomeprazole $20 \mathrm{mg}$ & 19.20 & $(7.46-48.91)$ & 19.45 & $(8.65-44.08)$ \\
\hline Esomeprazole $10 \mathrm{mg}$ & 3.34 & $(1.10-10.03)$ & 3.19 & $(1.16-8.74)$ \\
\hline Rabeprazole $20 \mathrm{mg}$ & 52.98 & $(14.54-202.76)$ & 34.09 & $(11.51-103.34)$ \\
\hline Rabeprazole $10 \mathrm{mg}$ & 8.08 & $(2.42-29.64)$ & 5.31 & $(1.75-16.63)$ \\
\hline Pantoprazole $40 \mathrm{mg}$ & 18.99 & $(3.96-91.38)$ & 19.09 & $(4.83-78.65)$ \\
\hline Lansoprazole $30 \mathrm{mg}$ & 18.88 & $(6.65-53.25)$ & 19.81 & $(8.06-49.11)$ \\
\hline Lansoprazole $15 \mathrm{mg}$ & 12.43 & $(5.21-29.43)$ & 12.45 & $(6.01-26.08)$ \\
\hline Omeprazole $20 \mathrm{mg}$ & 9.54 & $(3.92-24.61)$ & 9.91 & $(4.52-23.15)$ \\
\hline Omeprazole $10 \mathrm{mg}$ & 5.04 & $(2.06-13.08)$ & 6.13 & $(2.79-14.66)$ \\
\hline Ranitidine $300 \mathrm{mg}$ twice daily & 2.50 & $(0.46-13.29)$ & 2.41 & $(0.45-12.97)$ \\
\hline Ranitidine $150 \mathrm{mg}$ twice daily & 1.66 & $(0.60-4.74)$ & 1.65 & $(0.66-4.31)$ \\
\hline DIC & 111.78 & & 111.35 & \\
\hline \multicolumn{5}{|c|}{ Subgroup analysis (end point was assessed at 6 months) } \\
\hline Vonoprazan $10 \mathrm{mg}$ & 32.04 & $(4.70-204.38)$ & 35.06 & $(7.12-188.10)$ \\
\hline Vonoprazan $20 \mathrm{mg}$ & 90.74 & $(11.69-700.64)$ & 99.68 & $(13.72-834.64)$ \\
\hline Dexlansoprazole $30 \mathrm{mg}$ & 8.31 & $(2.24-30.51)$ & 8.38 & $(2.83-25.00)$ \\
\hline Esomeprazole $20 \mathrm{mg}$ & 15.13 & $(5.91-41.39)$ & 15.75 & $(6.94-39.02)$ \\
\hline Esomeprazole $10 \mathrm{mg}$ & 3.08 & $(1.17-7.80)$ & 3.12 & $(1.40-6.98)$ \\
\hline Rabeprazole $20 \mathrm{mg}$ & 23.36 & $(8.41-68.37)$ & 23.69 & $(9.67-60.89)$ \\
\hline Rabeprazole $10 \mathrm{mg}$ & 10.10 & $(3.78-26.79)$ & 10.16 & $(4.39-23.52)$ \\
\hline Lansoprazole $30 \mathrm{mg}$ & 12.53 & $(1.83-84.77)$ & 13.53 & $(2.60-75.79)$ \\
\hline Lansoprazole $15 \mathrm{mg}$ & 8.41 & $(2.28-30.36)$ & 8.96 & $(3.09-28.28)$ \\
\hline Omeprazole $20 \mathrm{mg}$ & 30.17 & $(7.93-216.59)$ & 33.52 & $(8.59-267.47)$ \\
\hline Omeprazole $10 \mathrm{mg}$ & 8.67 & $(3.38-35.52)$ & 8.52 & $(3.62-28.53)$ \\
\hline Ranitidine $300 \mathrm{mg}$ twice daily & 1.20 & $(0.18-7.75)$ & 1.28 & $(0.20-8.65)$ \\
\hline
\end{tabular}

$C I$ credible interval, DIC deviance information criterion 

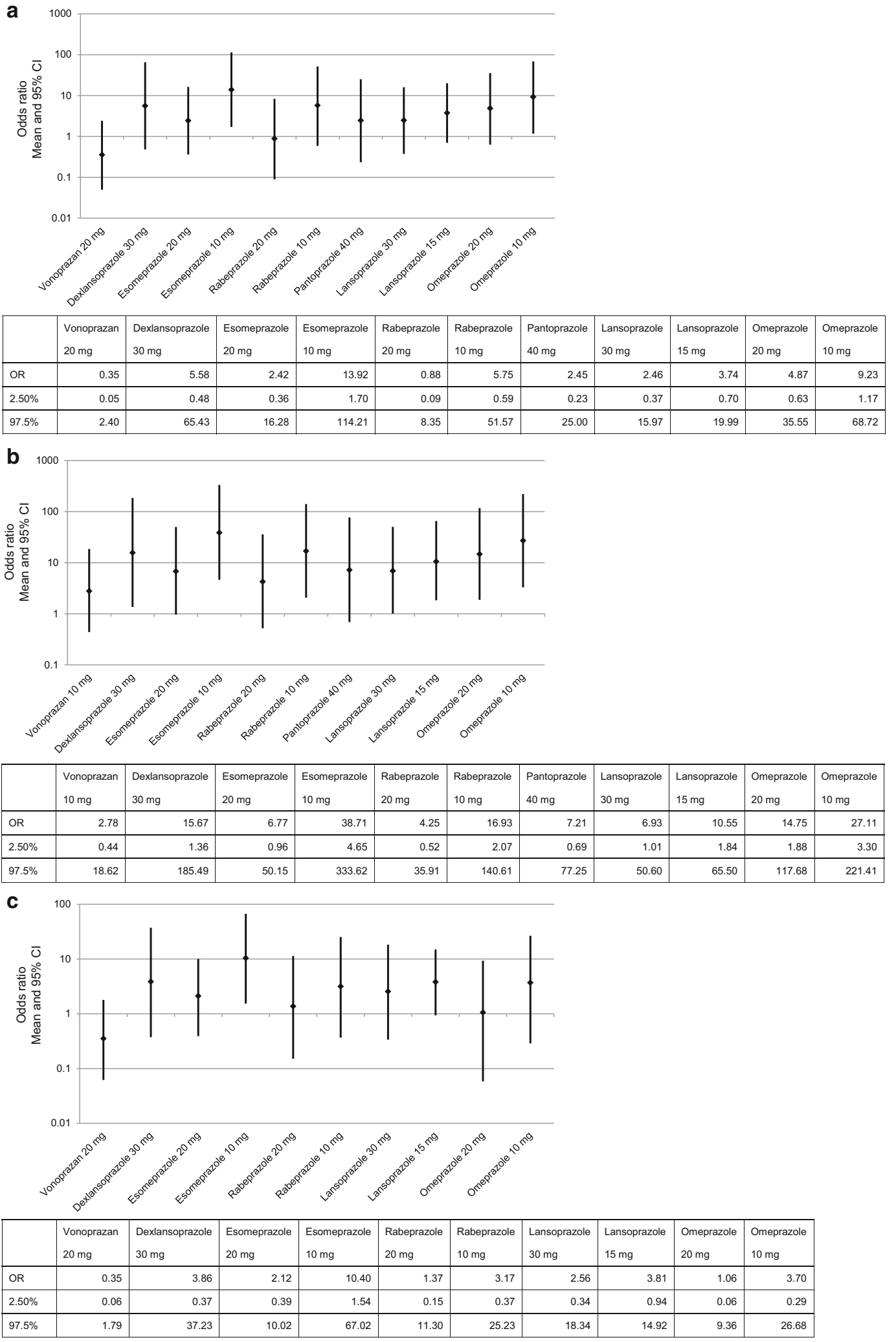

Fig. 4 Odds ratio of maintenance effect of vonoprazan to PPIs: a vonoprazan $10 \mathrm{mg}$ to PPIs in main analysis (the latest end point was assessed), b vonoprazan $20 \mathrm{mg}$ to PPIs in main analysis, and c vonoprazan $10 \mathrm{mg}$ to PPIs in subgroup analysis (end point was assessed at 6 months). $C I$ credible interval, $O R$ odds ratio, PPIs proton-pump inhibitors 
esomeprazole $10 \mathrm{mg}$ and omeprazole $10 \mathrm{mg}$. This indicates that although vonoprazan $10 \mathrm{mg}$ was insufficient to demonstrate higher GERD maintenance effect than the PPIs prescribed in Japan, increasing the dose to $20 \mathrm{mg}$ may be effective. The observation period varied from 6 months to 5 years ( 260 weeks). In the subgroup analysis with 6 months of observation period, the results between the main analysis and subgroup analysis were consistent for most of the treatments, indicating the consistency of OR between each treatment regardless of the observation period.

The ORs calculated from the RCT comparing vonoprazan $10 \mathrm{mg}$ to lansoprazole $15 \mathrm{mg}$ and vonoprazan $20 \mathrm{mg}$ to lansoprazole $15 \mathrm{mg}$ conducted by Umegaki et al. [10] were 3.79 and 9.97, respectively. These ratios were comparable to the values shown in this network metaanalysis (3.74 and 10.55), indicating that the analysis is valid. Notably, however, the GERD maintenance effect with vonoprazan $10 \mathrm{mg}$ was not significantly higher than that with lansoprazole $15 \mathrm{mg}$, despite the fact that lansoprazole $15 \mathrm{mg}$ is half of the approved dose [42]. In contrast, the GERD maintenance effect with vonoprazan $10 \mathrm{mg}$ was significantly higher than that with esomeprazole $10 \mathrm{mg}$ and omeprazole $10 \mathrm{mg}$, which were also both administered at half their approved doses [43, 44]. To our knowledge, only one head-to-head trial of vonoprazan $10 \mathrm{mg}$ and lansoprazole $15 \mathrm{mg}$ has been reported [10], which we consider to account for the broad confidence interval (OR 3.74 [95\% CI 0.70-19.99]) in the present network meta-analysis. In addition, the head-to-head trial reported the superiority of vonoprazan $10 \mathrm{mg}$ and $20 \mathrm{mg}$ to lansoprazole $15 \mathrm{mg}$ for the recurrence rate of erosive esophagitis during a 24-week maintenance period [10]. Therefore, once more studies of different maintenance therapies become available, we expect the confidence intervals of the ORs between these therapies to, in turn, become more accurate.

Previously, Li et al. [45] and Zhang et al. [46] reported the comparative efficacy of different PPIs in healing GERD and relieving its symptoms, as well as the acceptability/tolerability of PPIs by network meta-analysis. However, to our knowledge, the comparative efficacy of different PPIs for the maintenance treatment of GERD and that of PPIs and vonoprazan have not been conducted to date. Since vonoprazan was launched in 2015, the Clinical Practice Guidelines for GERD, which were revised in 2015, do not include any information on treatment with vonoprazan. Therefore, the findings of this study may be useful for the treatment of GERD patients with repeated relapse.

There are several limitations to this study. Firstly, literature-based meta-analyses include heterogeneity and bias based on each study. Secondly, the maintenance rates were described by different methods in the studies. Therefore, we performed sensitivity analyses to examine the robustness of the results by excluding studies with high risk of bias, studies that used different methods to calculate the remission rate, or studies that used a different definition for maintenance. A difference was observed in the analysis that included only studies with a high standard of maintenance from main analysis. Thirdly, we used only MEDLINE and CENTRAL for the literature search and did not use other data sources, such as EMBASE, owing to lack of access, which may cause a potential bias. Fourthly, we did not identify the race of patients in this study. Owing to an increase in patients with GERD in Asia, including Japan [47-50], further studies focusing on this area should be conducted. In this network meta-analysis, we did not perform subgroup analysis of RCTs with Asian subjects owing to insufficient number of studies. A further limitation was that few studies contained the Los Angeles scale for endoscopic assessment, which meant that the impact of the grade of reflux esophagitis before GERD therapy on maintenance therapy could not be assessed. Finally, few studies reported CYP2C19 evaluation, which meant that the impact of genetic polymorphism on agents other than vonoprazan and rabeprazole, and in turn maintenance therapy, could not be assessed [51, 52].

According to our network meta-analysis, the maintenance effect of vonoprazan for GERD is likely to be higher than that of some PPIs. Given that the information currently available on the comparative efficacy of vonoprazan and other PPIs for GERD maintenance is inadequate, we believe that the findings of this study would be useful in selecting a more effective treatment for patients with GERD. However, further direct head-to-head comparison trials of vonoprazan and other PPIs are required to confirm the efficacy of vonoprazan for maintenance treatment of erosive esophagitis.

Acknowledgements This study was funded by Takeda Pharmaceutical Company Ltd. Support in writing the manuscript, in literature search, and in data analysis was provided by Tomomi Takeshima, $\mathrm{PhD}$, Wentao Tang, PhD, and Yujiro Otsuka and Kosuke Iwasaki, employees of Milliman, respectively, and funded by Takeda Pharmaceutical Company Ltd. The authors would also like to thank Shinzo Hiroi, PhD, at the time employed by Takeda Pharmaceutical Co., Ltd., for contribution to study design and interpretation of data. We would like to thank Editage (www.editage.jp) for English language editing.

Author contributions HM, AI, LT, AU, HD, and TT designed the study; AI and LT collected and interpreted the study data. All authors critically revised the manuscript and approved the final version of the article, including the authorship list.

\section{Compliance with ethical standards}

Conflict of interest Hiroto Miwa has received research funding from Takeda Pharmaceutical Company, Ltd., Otsuka Pharmaceutical Company, Ltd., Daiichi Sankyo Company, Ltd., and Eisai Co., Ltd., 
and honorarium from Takeda Pharmaceutical Company, Ltd., Otsuka Pharmaceutical Company, Ltd., Daiichi Sankyo Company, Ltd., Eisai Co., Ltd., and AstraZeneca K. K.; Ataru Igarashi has received research grants from Pfizer Japan Inc., CSL Behring Japan Inc., Gilead Science K. K., and Fuji Film K. K., consulting fees from Novartis Pharma K. K., AbbVie GK, Milliman, Sony Inc., and Eli Lilly Japan K. K., and lecture fees from Chugai Pharmaceutical Company, Ltd., CRECON Research and Consulting Inc., Terumo Corporation, Bristol-Myers Squibb K. K., and Creativ-Ceutical K. K.; Toshiro Tango has received consulting fees from Takeda Pharmaceutical Company, Ltd., AbbVie GK, Ajinomoto Pharma, and Lion Corporation; Akihito Uda and Hisato Deguchi are employees of Takeda Pharmaceutical Company, Ltd.; Lida Teng has no conflict of interest.

Open Access This article is distributed under the terms of the Creative Commons Attribution 4.0 International License (http://crea tivecommons.org/licenses/by/4.0/), which permits unrestricted use, distribution, and reproduction in any medium, provided you give appropriate credit to the original author(s) and the source, provide a link to the Creative Commons license, and indicate if changes were made.

\section{References}

1. Locke GR III. Natural history of nonerosive reflux disease. Gastroenterol Clin North Am. 2002;31:S59-66.

2. DeVault KR, Castell DO. Updated guidelines for the diagnosis and treatment of gastroesophageal reflux disease. Am J Gastroenterol. 2005;100:190-200.

3. Olbe L, Lundell L. Medical treatment of reflux esophagitis. Hepatogastroenterology. 1992;39:322-4.

4. Freston JW, Malagelada JR, Petersen $\mathrm{H}$, et al. Critical issues in the management of gastroesophageal reflux disease. Eur J Gastroenterol Hepatol. 1995;7:577-86.

5. Schwizer W, Fried M. Gastroesophageal reflux. Ther Umsch. 1997;54:611-6.

6. Richter JE. Long-term management of gastroesophageal reflux disease and its complications. Am J Gastroenterol. 1997;92:30S$5 \mathrm{~S}$.

7. Peghini PL, Katz PO, Bracy NA, et al. Nocturnal recovery of gastric acid secretion with twice-daily dosing of proton pump inhibitors. Am J Gastroenterol. 1998;93:763-7.

8. Hori Y, Matsukawa J, Takeuchi T, et al. A study comparing the antisecretory effect of TAK-438, a novel potassium-competitive acid blocker, with lansoprazole in animals. J Pharmacol Exp Ther. 2011;337:797-804.

9. Dent J, Kahrilas PJ, Hatlebakk J, et al. A randomized, comparative trial of a potassium-competitive acid blocker (AZD0865) and esomeprazole for the treatment of patients with nonerosive reflux disease. Am J Gastroenterol. 2008;103:20-6.

10. Umegaki E, Iwakiri K, Hiramatsu N, et al. Tu1052 a phase 3, randomized, double-blind, multicenter study to evaluate the efficacy and safety of TAK-438 (10 mg or $20 \mathrm{mg}$ once-daily) compared to lansoprazole (15 mg once-daily) in a 24-week maintenance treatment for healed erosive esophagitis. Gastroenterology. 2014;146:S-738.

11. Higgins JPT, Green S. Cochrane handbook for systematic reviews of interventions. version 5.1.0. 2011. www.handbook. cochrane.org. Accessed 4 June 2018.

12. Moher D, Liberati A, Tetzlaff J, et al. Preferred reporting items for systematic reviews and meta-analyses: the PRISMA statement. PLOS Med. 2009;6:e1000097.
13. Hutton B, Salanti G, Caldwell DM, et al. The prisma extension statement for reporting of systematic reviews incorporating network meta-analyses of health care interventions: checklist and explanations. Ann Intern Med. 2015;162:777-84.

14. White IR, Barrett JK, Jackson D, et al. Consistency and inconsistency in network meta-analysis: model estimation using multivariate meta-regression. Res Synth Methods. 2012;3:111-25.

15. Lu G, Ades A. Modeling between-trial variance structure in mixed treatment comparisons. Biostatistics. 2009;10:792-805.

16. Dias S, Welton NJ, Sutton AJ, et al. Evidence synthesis for decision making 1: introduction. Med Decis Making. 2013;33:597-606.

17. Spiegelhalter DJ, Best NG, Carlin BP, et al. Bayesian measures of model complexity and fit. J R Statist Soc B. 2002;64:583-639.

18. Armstrong D, Bennett JR, Blum AL, et al. The endoscopic assessment of esophagitis: a progress report on observer agreement. Gastroenterology. 1996;111:85-92.

19. Hetzel DJ, Dent J, Reed WD, et al. Healing and relapse of severe peptic esophagitis after treatment with omeprazole. Gastroenterology. 1988;95:903-12.

20. Sontag SJ, Kogut DG, Fleischmann R, et al. Lansoprazole prevents recurrence of erosive reflux esophagitis previously resistant to H2-RA therapy. The Lansoprazole Maintenance Study Group. Am J Gastroenterol. 1996;91:1758-65.

21. Caos A, Moskovitz M, Dayal Y, et al. Rabeprazole for the prevention of pathologic and symptomatic relapse of erosive or ulcerative gastroesophageal reflux disease. Rebeprazole Study Group. Am J Gastroenterol. 2000;95:3081-8.

22. Birbara C, Breiter J, Perdomo C, et al. Rabeprazole for the prevention of recurrent erosive or ulcerative gastro-oesophageal reflux disease. Rabeprazole Study Group. Eur J Gastroenterol Hepatol. 2000;12:889-97.

23. Caos A, Breiter J, Perdomo C, et al. Long-term prevention of erosive or ulcerative gastro-oesophageal reflux disease relapse with rabeprazole 10 or $20 \mathrm{mg}$ vs. placebo: results of a 5-year study in the United States. Aliment Pharmacol Ther. 2005;22:193-202.

24. Laursen LS, Havelund T, Bondesen S, et al. Omeprazole in the long-term treatment of gastro-oesophageal reflux disease. A double-blind randomized dose-finding study. Scand J Gastroenterol. 1995;30:839-46.

25. Lauritsen K, Deviere J, Bigard MA, et al. Esomeprazole $20 \mathrm{mg}$ and lansoprazole $15 \mathrm{mg}$ in maintaining healed reflux oesophagitis: metropole study results. Aliment Pharmacol Ther. 2003;17:333-41.

26. Vakil NB, Shaker R, Johnson DA, et al. The new proton pump inhibitor esomeprazole is effective as a maintenance therapy in GERD patients with healed erosive oesophagitis: a 6-month, randomized, double-blind, placebo-controlled study of efficacy and safety. Aliment Pharmacol Ther. 2001;15:927-35.

27. Johnson DA, Benjamin SB, Vakil NB, et al. Esomeprazole once daily for 6 months is effective therapy for maintaining healed erosive esophagitis and for controlling gastroesophageal reflux disease symptoms: a randomized, double-blind, placebo-controlled study of efficacy and safety. Am J Gastroenterol. 2001;96:27-34.

28. Devault KR, Johanson JF, Johnson DA, et al. Maintenance of healed erosive esophagitis: a randomized six-month comparison of esomeprazole twenty milligrams with lansoprazole fifteen milligrams. Clin Gastroenterol Hepatol. 2006;4:852-9.

29. Annibale B, Franceschi M, Fusillo M, et al. Omeprazole in patients with mild or moderate reflux esophagitis induces lower relapse rates than ranitidine during maintenance treatment. Hepatogastroenterology. 1998;45:742-51.

30. Metz DC, Howden CW, Perez MC, et al. Clinical trial: dexlansoprazole MR, a proton pump inhibitor with dual delayed-release 
technology, effectively controls symptoms and prevents relapse in patients with healed erosive oesophagitis. Aliment Pharmacol Ther. 2009;29:742-54.

31. Bardhan KD, Cherian P, Vaishnavi A, et al. Erosive oesophagitis: outcome of repeated long term maintenance treatment with low dose omeprazole $10 \mathrm{mg}$ or placebo. Gut. 1998;43:458-64.

32. Gough AL, Long RG, Cooper BT, et al. Lansoprazole versus ranitidine in the maintenance treatment of reflux oesophagitis. Aliment Pharmacol Ther. 1996;10:529-39.

33. Richter JE, Fraga P, Mack M, et al. Prevention of erosive oesophagitis relapse with pantoprazole. Aliment Pharmacol Ther. 2004;20:567-75.

34. Metz DC, Bochenek WJ, Pantoprazole US GERD Study Group. Pantoprazole maintenance therapy prevents relapse of erosive oesophagitis. Aliment Pharmacol Ther. 2003;17:155-64.

35. Thjodleifsson B, Beker JA, Dekkers C, et al. Rabeprazole versus omeprazole in preventing relapse of erosive or ulcerative gastroesophageal reflux disease: a double-blind, multicenter, European trial. The European Rabeprazole Study Group. Dig Dis Sci. 2000;45:845-53.

36. Peura DA, Freston JW, Haber MM, et al. Lansoprazole for longterm maintenance therapy of erosive esophagitis: double-blind comparison with ranitidine. Dig Dis Sci. 2009;54:955-63.

37. Robinson M, Lanza F, Avner D, et al. Effective maintenance treatment of reflux esophagitis with low-dose lansoprazole. A randomized, double-blind, placebo-controlled trial. Ann Intern Med. 1996;124:859-67.

38. Bate CM, Booth SN, Crowe JP, et al. Omeprazole $10 \mathrm{mg}$ or $20 \mathrm{mg}$ once daily in the prevention of recurrence of reflux oesophagitis. Solo Investigator Group. Gut. 1995;36:492-8.

39. Hallerback B, Unge P, Carling L, et al. Omeprazole or ranitidine in long-term treatment of reflux esophagitis. The Scandinavian Clinics for United Research Group. Gastroenterology. 1994;107:1305-11.

40. Hatlebakk JG, Berstad A. Lansoprazole 15 and $30 \mathrm{mg}$ daily in maintaining healing and symptom relief in patients with reflux oesophagitis. Aliment Pharmacol Ther. 1997;11:365-72.

41. Vigneri S, Termini R, Leandro G, et al. A comparison of five maintenance therapies for reflux esophagitis. N Engl J Med. 1995;333:1106-10.

42. Pharmaceuticals and Medical Devices Agency (PMDA). Lansoprazole OD tablets $15 \mathrm{mg}$ "TOWA"/OD tablets $30 \mathrm{mg}$ "TOWA". Accessed 18 Jan 2019. 2017.
43. Pharmaceuticals and Medical Devices Agency (PMDA). Omeprazole $10 \mathrm{mg} / 20 \mathrm{mg}$ capsules. Accessed 18 Jan 2019. 2017.

44. Pharmaceuticals and Medical Devices Agency (PMDA). Esomeprazole $10 \mathrm{mg} / 20 \mathrm{mg}$ capsules. Accessed 18 Jan 2019. 2018.

45. Li MJ, Li Q, Sun M, et al. Comparative effectiveness and acceptability of the FDA-licensed proton pump inhibitors for erosive esophagitis: a PRISMA-compliant network meta-analysis. Med (Baltim). 2017;96:e8120.

46. Zhang C, Kwong JS, Yuan RX, et al. Effectiveness and tolerability of different recommended doses of PPIs and H2RAs in GERD: network meta-analysis and GRADE system. Sci Rep. 2017;7:41021.

47. Miwa H, Oshima T, Tomita T, et al. Gastro-esophageal reflux disease: the recent trend in Japan. Clin J Gastroenterol. 2008;1:133-8.

48. Fujiwara Y, Arakawa T. Epidemiology and clinical characteristics of GERD in the Japanese population. J Gastroenterol. 2009;44:518-34.

49. Kinoshita Y, Adachi K, Hongo M, et al. Systematic review of the epidemiology of gastroesophageal reflux disease in Japan. J Gastroenterol. 2011;46:1092-103.

50. Jang SH, Ryu HS, Choi SC, et al. Psychological factors influence the gastroesophageal reflux disease (GERD) and their effect on quality of life among firefighters in South Korea. Int J Occup Environ Health. 2016;22:315-20.

51. Kagami T, Sahara S, Ichikawa H, et al. Potent acid inhibition by vonoprazan in comparison with esomeprazole, with reference to CYP2C19 genotype. Aliment Pharmacol Ther. 2016;43:1048-59.

52. Lim PW, Goh KL, Wong BC. CYP2C19 genotype and the PPIs-focus on rabeprazole. J Gastroenterol Hepatol. 2005;20(Suppl):S22-8.

53. Dent J, Yeomans ND, Mackinnon M, et al. Omeprazole v ranitidine for prevention of relapse in reflux oesophagitis. A controlled double blind trial of their efficacy and safety. Gut. 1994;35:590-8.

54. Lundell L, Backman L, Ekstrom P, et al. Prevention of relapse of reflux esophagitis after endoscopic healing: the efficacy and safety of omeprazole compared with ranitidine. Scand J Gastroenterol. 1991;26:248-56.

Publisher's Note Springer Nature remains neutral with regard to jurisdictional claims in published maps and institutional affiliations. 